\title{
O ESTADO DEMOCRÁTICO DE DIREITO E A TRIBUTAÇÃO: ENTRE OS DIREITOS E DEVERES FUNDAMENTAIS NA (RE)CONSTRUÇÃO DE UMA SOCIEDADE SOLIDÁRIA A PARTIR DO DEVER FUNDAMENTAL DE PAGAR TRIBUTOS
}

\begin{abstract}
Marciano Buffon
Doutor em Direito - ênfase em Direito do Estado - pela UNISINOS, com período de pesquisa na Universidade de Coimbra - Mestre em Direito Público. Advogado Tributarista, com especialização em Direito Empresarial, Professor de Direito Tributário na UNISINOS, São Leopoldo/RS, e em cursos de pós-graduação (especialização) em Direito Tributário noutras instituições. Professor no Programa de Pós-Graduação em Direito Mestrado - da UNISINOS. Sócio/Consultor jurídico-fiscal Buffon \& Furlan Advogados Associados. Membro do Conselho Técnico de Assuntos Tributários, Legais e Financeiros da Federação das Indústrias do Estado do Rio Grande do Sul - FIERGS.

marciano@lucini.com.br
\end{abstract}

\section{Lilian Ramos Jacob}

Mestranda em Direito pelo Programa de Pós-Graduação em Direito da Unisinos, com bolsa de financiamento Capes. Possui Especialização em Direito do Estado pela Fundação Escola Superior do Ministério Público/RS. Graduada no curso de Direito pela Universidade do Vale do Rio do Sinos (Unisinos). Foi bolsista de Iniciação Científica, Monitora e Bolsista de Desenvolvimento Tecnológico Industrial pelo $\mathrm{CNPq}$, na Unisinos. Advogada inscrita na OAB/RS. lilianramosjacob@gmail.com

RESUMO: O artigo tem como objetivo principal analisar o dever fundamental de pagar tributos no Estado Democrático de Direito a partir da Constituição Federal brasileira de 1988. A partir disso, rumar-se-á ao enfrentamento da seguinte questão: De que forma a tributação pode contribuir para a (re)construção de uma sociedade solidária no atual Estado Democrático de Direito, notadamente, quanto ao resgate do dever fundamental de pagar tributos? O trabalho se desenvolve com pesquisa bibliográfica, especificamente, com consulta doutrinária sobre o tema.

PALAVRAS-CHAVE: Estado Democrático; Tributação; Dever fundamental.

The democratic state of law and taxation: among the fundamental rights and duties in (re)construction of a society solidarity of fundamental duty payable from taxes

ABSTRACT: This article aims to analyze the fundamental duty to pay taxes in the democratic rule of law from the Brazilian Federal Constitution of 1988. From this, it will be head to face

Recebido em: 6 set. 2016. Avaliado em: 14 e 22 nov. 2016. 
O estado democrático de direito e a tributação: entre os direitos e deveres fundamentais na (re)construção de uma sociedade solidária a partir do dever fundamental de pagar tributos

the question: How does taxation can contribute for (re)building a harmonious society in the current democratic rule of law, notably concerning the recovery of the fundamental duty to pay taxes? The work develops with literature, specifically with doctrinal consultation on the subject. KEYWORDS: Democratic State; Taxation; Fundamental duty.

\section{INTRODUÇÃO}

O artigo busca analisar o dever fundamental de pagar tributos no atual Estado Democrático de Direito, resgatando os vínculos de solidariedade, indispensável para a estruturação de uma sociedade justa.

Sendo assim, o problema que se propõe é: de que forma a tributação pode contribuir para a (re)construção de uma sociedade solidária no atual Estado Democrático de Direito, notadamente, quanto ao resgate do dever fundamental de pagar tributos?

Para isso, o trabalho se desenvolve com pesquisa bibliográfica, especificamente, com consulta doutrinária sobre o tema. Foram utilizadas obras nacionais e estrangeiras.

Justifica-se o artigo, tendo em vista que a tributação constitui meio de concretizar os direitos fundamentais, uma vez que sem a devida contribuição financeira, não há realização de políticas sociais. Eis a razão do dever fundamental de pagar tributos, pois efetiva os vínculos de solidariedade entre os indivíduos numa sociedade.

Primeiramente, analisa-se o Estado de Direito e o Constitucionalismo, fazendo-se referência aos períodos do Estado Liberal, Estado Social e Estado Democrático de Direito. Após, num segundo momento, aborda-se a questão dos direitos e deveres na construção de uma sociedade solidária. E, por final, se examina o dever fundamental de pagar tributos como instrumento de concretização de direitos.

\section{O ESTADO DE DIREITO E O CONSTITUCIONALISMO}

O Estado de Direito surge a partir da segunda metade do século XIX, em suas mais variantes formas europeias, como, por exemplo, o Rechtstaat, na Alemanha, e o Rule of Law, na Inglaterra, vinculado a uma necessidade de institucionalização jurídica, com o objetivo de limitar o poder do Estado pelo Direito. Assim, no Estado de Direito "o outrora poder ilimitado passa por uma limitação do exercício das suas funções potestativas cujo objetivo é torná-lo compatível com os direitos individuais de liberdade" (TEIXEIRA, 2011, p. 112-113).

Deve-se ter presente a definição de Estado de Direito para Fioravanti (2001, p. 140), ao constatar:

[...] en la cultura constitucional del siglo XIX, que coincidiera la soberanía del Es-
tado con la soberanía del ordenamiento jurídico dado por ese mismo Estado, que con
sus reglas anulaba la soberanía política del monarca o del pueblo, transformándola
en poderes jurídicamente regulados, insertos en ese mismo ordenamiento. En pocas
palabras, esto es el Estado de Derecho.

Em decorrência desta limitação do poder do Estado pelo Direito, que a Constituição surge com fundamental importância, já que define as atuações do Estado, estabelece os limites, as formações dos órgãos, e, notadamente, como se situam os particulares, com seus direitos frente ao Estado. Por isso, "la relación entre Estado y Constitución es tan estrecha que hace imposible 
la existencia del Estado sin constitución, pero también de la constitución sin Estado" (FIORAVANTI, 2001, p. 142).

Desse modo, o Estado de Direito emerge como o Estado que se submete ao regime de direito, ou seja, a atividade estatal desenvolver-se a parir da utilização de instrumento regulado e autorizado pela ordem jurídica, e, os indivíduos, por sua vez, têm a seu dispor mecanismos jurídicos aptos a salvaguardar-lhes de uma ação abusiva do Estado (STRECK, 2014, p. 91-92).

Porém, este Estado é mais que um Estado jurídico/legal, isto é, não basta que tenha normatividade, já que ao Estado de Direito agregam-se conteúdos. Não está limitado em uma concepção formal de uma ordem jurídica, sobretudo, é "um conjunto de direitos fundamentais próprios de uma determinada tradição" (STRECK, 2014, p. 92-93).

Nas palavras de Zagrebelsky, o Estado de Direito indica um valor, isto é, "El valor es la eliminación de la arbitrariedad en el ámbito de la actividad estatal que afecta a los ciudadanos" (2011, p. 21). Isto é, não bastava que existisse a lei, uma vez que esta poderia ser utilizada sob influência do domínio totalitário sobre a sociedade. Portanto, era preciso que a lei garantisse os direitos dos cidadãos (ZAGREBELSKY, 2011, p. 23).

Assim, o Estado de Direito se apresentará, primeiramente, como Estado Liberal de Direito, em um segundo momento, como Estado Social de Direito e após, como Estado Democrático de Direito. Cada um deles moldará o Direito conforme seu conteúdo, sem que haja, contudo, uma ruptura entre eles.

\subsection{Estado Liberal de Direito}

A construção do Estado Liberal de Direito parte da concepção da sociedade com suas próprias exigências, e não da autoridade do Estado, a lei passa a ser concebida como instrumento de garantia dos direitos dos cidadãos, como forma de protegê-los das arbitrariedades da Administração (ZAGREBELSKY, 2011, p. 23).

Assim, o Estado de Direito surge aliado ao conteúdo do liberalismo, com submissão da soberania a lei, a divisão de poderes ou funções, e, em especial, a garantia dos direitos individuais (STRECK, 2014, p. 95).

O ideário liberal, portanto, nasce da necessidade de, além de estabelecer limites ao até então ilimitado poder soberano exercido pelo monarca, também, possibilitar respeito aos direitos dos cidadãos, que passam a ser constitucionalmente inclusos e garantidos nas Cartas que se sucedem (TEIXEIRA, 2011. p. 112).

Assim, o sentido geral do Estado Liberal de Direito consiste "en el condicionamiento de la autoridad de Estado a la libertad de la sociedad, em el marco del equilibrio recíproco estabelecido por la ley" (ZAGREBELSKY, 2011, p. 23).

O surgimento do constitucionalismo, portanto, tem profunda ligação com a era das Revoluções, notadamente, a Francesa e a Americana, que expressaram a luta dos cidadãos pelo reconhecimento de seus direitos de liberdades individuais frente ao Estado (BINENBOJM, 2004, p. 15-20).

Portanto, as Revoluções do pensamento liberal pretendiam enunciar um mínimo irredutível do Direito, que evidenciasse verdades universais, justificadas pela razão, porém não dispensava as declarações solenes, quando deram início as Declarações de Direitos, da Virgínia, em 1776, e a 
O estado democrático de direito e a tributação: entre os direitos e deveres fundamentais na (re)construção de uma sociedade solidária a partir do dever fundamental de pagar tributos

Declaração dos Direitos do Homem e do Cidadão, em 1789, na França, que marcaram o reconhecimento dos direitos dos cidadãos (FERREIRA FILHO, 1999, p. 14-15).

Pode-se dizer que, tanto na França, como na América do Norte, "visavam a estabelecer o ponto de referência, o padrão, em função do qual todas as instituições e leis fossem medidas quanto à sua justeza, todos os homens soubessem quais eram os seus direitos e até onde iam" (FERREIRA FILHO, 1999, p. 15).

Já, o modelo anglo-saxão do rule of law, não tinha como objetivo estabelecer um limite ao poder do monarca como na França, que já estava enfraquecido desde o Glorious Revolution de 1688, mas sim restringir o poder soberano do parlamento, a partir do Common Law, característico do direito amparado nos princípios e costumes, restando a tutela dos direitos dos cidadãos ao judiciário, com a finalidade de evitar arbitrariedades (TEIXEIRA, 2011, p. 114).

Nesse sentido, as constituições e declarações de direitos desse período representaram a consagração de uma primeira geração de direitos individuais, como os direitos de liberdade, propriedade, segurança, e o direito ao voto. Também, ligado a estes reconhecimentos, e, sobremaneira, de ampla notoriedade, sobreveio a tutela internacional dos direitos humanos (TEIXEIRA, 2011, p. 117).

É nesse momento que "declara-se, então, que os homens nascem e permanecem livres e iguais em direitos" (DALLARI, 2011. p. 150). Ou seja, as limitações que serão impostas aos indivíduos advirão apenas da lei, que é a expressão da vontade geral de todos os cidadãos.

Contudo, como o direito ao voto não era ainda um direito que competia à grande parcela da população, o monopólio do poder legislativo permanecia com quem detinha mais poder. Assim, Zagrebelsky ressalta que "El proletariado y sus movimientos políticos eran mantenidos alejados del Estado mediante la limitación del derecho de voto" (2011, p. 32), e que "en este panorama, el monopolio-legislativo de uma clase social relativamente homogénea determinaba por si mismo las condiciones de la unidad de la legislación" (2011, p. 32).

Nesse contexto, a Constituição surge como instrumento de garantia de direitos fundamentais, além de constituir um Estado. Assim, "esta imprime no Estado a reta organização, a qual deverá impedir o abuso, isto é, a violação pelos órgãos estatais dos direitos do homem”. Além disso, "por outro lado, esta reta organização põe o Estado a serviço da finalidade que o legitima, a defesa desses direitos na vida social cotidiana" (FERREIRA FILHO, 1999, p. 19).

Destarte, o processo em que se dará a institucionalização do constitucionalismo partirá da restrição e limitação do poder dos que o detém. Assim sendo, Karl Loewenstein (1979, p. 29) afirma que o constitucionalismo é:

\footnotetext{
Un acuerdo de la comunidad sobre una serie de reglas fijas que obligan tanto a los detentadores como a los destinatarios del poder, se ha mostrado como el mejor medio para dominar y evitar el abuso del poder político por parte de sus detentadores. El mecanismo de esas reglas que están, ya formuladas en un documento formal, la constitución, ya profundamente enraizadas en las costumbres y conciencia nacional [...].
}

A Constituição surgirá como "uma garantia dos direitos fundamentais do homem" (FERREIRA FILHO, 1999, p. 18). Ou seja, a Constituição garante esses direitos aos cidadãos frente ao Estado, e, ao mesmo tempo, é Lei Magna deste Estado, estabelecendo sua organização funcional (FERREIRA FILHO, 1999, p. 18).

Para Otto Bachof (1994, p. 39), a Constituição em sentido material entende-se em geral como "o conjunto das normas jurídicas sobre a estrutura, atribuições e competências dos órgãos supremos do Estado, sobre as instituições fundamentais do Estado e sobre a posição do cidadão no Estado". Já, a Constituição em sentido formal será: 
[...] uma lei formal qualificada essencialmente através de características formaisparticularidades do processo de formação e da designação, maior dificuldade de alteração- ou também uma pluralidade de tais leis: corresponderá, portanto, ao conteúdo global, muitas vezes mais ou menos acidental, das disposições escritas da Constituição (1994, p. 39).

Contudo, ao passar dos séculos, o Direito teve a necessidade de incluir em seu compêndio os direitos sociais e coletivos ante as exigências da sociedade. Assim, parte-se à verificação do Estado Social de Direito.

\subsection{Estado Social de Direito}

O Estado Social busca o bem-estar da coletividade, e, sendo assim, o desenvolvimento social marcam as ações do ente público. A lei, portanto, passa de uma ordem geral e abstrata para uma destinação específica e concreta, ou seja, a lei passa a ser instrumento de ação, com objetivo de atender critérios circunstanciais (STRECK, 2014, p. 97).

A partir do século XX, o Estado, por influência dos socialistas e cristãos -sociais, cunhou a tarefa de providência dos malsucedidos. Por isso, chamou-se Estado-Providência, de forma a dar a todos condições adequadas de vida pela intervenção no domínio econômico e social (FERREIRA FILHO, 1999, p. 40).

Assim, "a consagração do chamado Estado-Social, ou Estado de Bem-Estar, depois da Segunda Guerra Mundial, leva muito adiante a tendência desenhada pelo intervencionismo" (FERREIRA FILHO, 1999, p. 40). Isto é, o Estado assume a postura de prover o bem para a sociedade.

Pretende, portanto, uma reformulação do Estado a partir de garantias coletivas, na busca de um equilíbrio não atingido pela sociedade liberal (STRECK, 2014, p. 103). Logo, a lei passa a ser utilizada para a promoção de prestações positivas na construção de uma ordem jurídica.

Ademais, o Estado de Bem-Estar Social vai reconhecer os direitos humanos fundamentais, porém, "desapoiados num direito transcendente, frágil é a situação deles, que depende de um "reconhecimento", uma proclamação — de caráter constitutivo - por parte do próprio Estado, a que limitariam" (FERREIRA FILHO, 1999, p. 44).

O Estado Social de Direito foi constitucionalizado, pela primeira vez, em 1949, na Alemanha, com a Lei Fundamental de Bonn, teve grande influências das classes trabalhadoras, exigindo o desenvolvimento de atividades econômicas e administrativas por parte do Estado em prol da sociedade (GARCÍA-PELAYO, 2009, p. 3-5).

Para García-Pelayo (2009, p. 6), o Estado Social significa "a tentativa de adaptação do Estado tradicional (pelo que entendemos, nesse caso, o Estado Liberal burguês) às condições sociais da civilização industrial e pós-industrial", que se desenvolveu a parir de política social "cujo objetivo imediato é remediar as péssimas condições de vida das camadas mais desamparadas e necessitadas da população" (2009, p. 6).

Após a Segunda Guerra Mundial se evidenciou profundas crises econômicas, com amplo desemprego, e lutas de classes. Para enfrentar tal situação, era necessário "aumentar a capacidade aquisitiva das massas, que atuaria, por sua vez, como causa do crescimento da produção e, por conseguinte, da oferta de emprego" (GARCÍA-PELAYO, 2009, p. 8). Isso só seria possível com a "orientação e controle do processo econômico por parte do Estado, mantendo-se a propriedade privada dos meios de produção" (GARCÍA-PELAYO, 2009, p. 8). 
O estado democrático de direito e a tributação: entre os direitos e deveres fundamentais na (re)construção de uma sociedade solidária a partir do dever fundamental de pagar tributos

Assim, a teoria econômica, a política e a política social formaram um todo, "dito de outra forma, tendem a transformar-se em subsistemas de um sistema superior. Isso quer dizer que cada um desses subsistemas é condicionado pelos demais, ao mesmo tempo em que os condiciona" (GARCÍA-PELAYO, 2009, p. 8). Isto é, transformou-se numa política socioeconômica sistêmica, pois seus componentes estão conectados entre si (GARCÍA-PELAYO, 2009, p. 9).

O que caracteriza um Estado Social é a justa distribuição do que foi produzido, e esta finalidade só é alcançada por meio da potestade fiscal. Assim, se conduz a um "Estado de prestações que assume a responsabilidade da distribuição e redistribuição de bens e serviços econômicos" (GARCÍA-PELAYO, 2009, p. 22).

Nessa ótica, a ideia social de Estado está vinculada aos problemas em torno da exigência de uma justiça distributiva, mais eficaz, e a necessidade de integração social.

Tendo em vista a evolução, principalmente dos direitos humanos, após 1945, “chegou-se enfim ao reconhecimento de que à própria humanidade, como um todo solidário, devem ser reconhecidos vários direitos" (COMPARATO, 2007. p. 56-58). Não apenas direitos individuais, de natureza civil e política, mas também direitos econômicos, sociais, e de humanidade.

Embora o Estado Social tenha inserido profundas transformações na sociedade, tanto no reconhecimento de outros direitos pelo Estado, como na atuação positiva para com o indivíduo, na tentativa de promover o bem social, a problemática em torno da igualdade não restou superada, tendo encontrado no Estado Democrático de Direito o seu fundamento.

\subsection{Estado Democrático de Direito}

O Estado Democrático de Direito surge como transformador da realidade, "o seu conteúdo ultrapassa o aspecto material de concretização de uma vida digna ao homem e passa a agir simbolicamente como fomentador da participação pública no processo de construção e reconstrução" (STRECK, 2014. p. 98), tendo em vista uma nova sociedade baseada na Constituição, como instrumento básico de garantia jurídica, uma organização democrática, um sistema de direitos fundamentais, que assegura autonomia dos indivíduos frente aos poderes públicos e justiça social para corrigir desigualdades (STRECK, 2014. p. 99).

Desse modo, o Estado Democrático de Direito é "plus normativo em relação às formulações anteriores" (STRECK, 2014. p. 100), ou seja, impõe à ordem jurídica e à atividade estatal um conteúdo utópico de transformação da realidade, já que teria a característica de ultrapassar não só a formulação do Estado Liberal de Direito, como também a do Estado Social de Direito (STRECK, 2014. p. 100).

Por conseguinte, o objetivo do Estado de Direito, quando assume o perfil democrático, é a igualdade, e a lei aparece como instrumento de transformação da sociedade, não estando mais atrelada à sanção ou promoção, mas sim a reestruturação das relações sociais. Permite-se, dessa forma, "a aparente redução das antíteses econômicas e sociais à unidade formal do sistema legal, principalmente através de uma Constituição, onde deve prevalecer o interesse da maioria" (STRECK, 2014, p. 101). Ainda, a Constituição é colocada no "ápice de uma pirâmide escalonada, fundamentando a legislação que, como tal, é aceita como poder legítimo" (STRECK, 2014, p. 101).

Em busca de condições mínimas de vida aos cidadãos e da comunidade, a problemática em torno da igualdade resta acentuada, já que se vincula a um projeto solidário, ou seja, a solidariedade passa a compor o caráter comunitário (STRECK, 2014, p. 104). 
Assim, há uma identificação do constitucionalismo do segundo pós-guerra e o paradigma do Estado Democrático, que aponta para "o resgate das promessas incumpridas da modernidade, circunstancias que assume especial relevância em países periféricos e de modernidade tardia como o Brasil" (STRECK, 2014, p. 105). A Constituição brasileira de 1988 é, portanto, voltada à transformação da realidade, depreende-se de seus princípios fundamentais fins sociais e econômicos, promovendo-se a integração da sociedade nacional (STRECK, 2014, p. 98).

Contudo, a crise de financiamento do Estado, notadamente pelo crescimento do déficit público, que emergiram desde as décadas de 1960 e 1970, com descompasso entre receitas e despesas, contribuíram para o enfraquecimento do Estado do Bem-Estar. E a partir dos anos 1980, buscou-se em um projeto neoliberal o caminho para a redução dessa crise, sobretudo, com as privatizações, cortes em gastos sociais e venda de patrimônio público com preços desvalorizados (STRECK, 2014, p. 157).

Em decorrência de todas essas transformações, o Estado Democrático de Direito vive uma crise, por conta de inúmeros direitos proclamados, de cunho social, em que o Estado deve dar conta, porém o orçamento já não comporta a realização das políticas públicas, que se concretizaria, em especial, com efetivos mecanismos de tributação.

\section{ENTRE OS DIREITOS E OS DEVERES PARA CONSTRUÇÃO DE UMA SOCIEDADE SOLIDÁRIA}

Como visto anteriormente, o Estado constitucional, portanto, desenvolveu-se tendo como característica a subordinação da legalidade a uma Constituição, ou seja, a validade das leis depende também da compatibilidade de seu conteúdo com as normas constitucionais.

O marco histórico do novo Direito Constitucional, no Brasil, nasce com a elaboração e promulgação da Constituição Federal de 1988, que assinalou a reconstitucionalização do país, tendo em vista que indica "a travessia de um regime autoritário, intolerante e, por vezes, violento para um Estado Democrático de Direito” (BARROSO, 2013, p. 268).

Neste período surge o pós-positivista, como marco filosófico do novo direito constitucional, o qual faz referência às ideias de justiça além da lei e de igualdade material mínima, ao lado da teoria dos direitos fundamentais e da redefinição de valores, princípios e regras, aspectos da nova hermenêutica (BARROSO, 2013, p. 269). Assim, esse novo direito constitucional pós segunda grande guerra, ou neoconstitucionalismo, é produto do reencontro da ciência jurídica e da filosofia do direito.

Por outro lado, como consequência de grande parcela das Constituições advindas do Estado Providência, após períodos de repressão e totalitarismos, sobrevieram uma gama de direitos fundamentais instituídos pelos Estados e por sua responsabilidade na realização dos mesmos. Não foi diferente com o Brasil, na Constituição de 1988, que previu inúmeros direitos aos indivíduos, porém, sem referir nos deveres.

Como muito bem explica Canotilho, as experiências históricas dos períodos após o ideário comunista, revelam Constituições com indiferença aos deveres fundamentais, sobrepondo, assim, os direitos fundamentais, como segue:

A República era o reino da virtude no sentido romano, que só pode funcionar se os cidadãos cumprem um certo número de deveres: servir a pátria, votar, ser solidário, aprender. Nesse sentido, a teoria da cidadania republicana implica que um indivíduo teria não apenas direitos, mas também deveres. Nos começos do século, sob a inspi- 
O estado democrático de direito e a tributação: entre os direitos e deveres fundamentais na (re)construção de uma sociedade solidária a partir do dever fundamental de pagar tributos

\begin{abstract}
ração da Constituição de Weimar, onde existia uma parte intitulada "Direitos fundamentais e Deveres fundamentais dos alemães", a doutrina juspublicista falava de igual dignidade de direitos e deveres fundamentais (Heller). Todavia, também já nesta altura não faltavam a considerar os deveres fundamentais como contrários à ideia de estado de direito liberal (Carl Schmitt). A centralidade da categoria de deveres fundamentais reaparece nas construções jurídico-políticas nacional-socialista e comunista. No ideário nazi, os deveres fundamentais dos cidadãos convertem-se em deveres fundamentais dos "membros do povo" (dever de serviço de poderes, dever de trabalhar, dever de defender o povo). Na compreensão comunista, os direitos fundamentais eram também relativizados pelos deveres fundamentais: os indivíduos tinham direitos conexos com deveres, o que, nos quadros políticos dos ex-países comunistas, acabou por aniquilar os direitos e hipertrofiar os deveres. Estas duas experiências históricas explicam a desconfiança e indiferença dos textos constitucionais em face dos deveres fundamentais (CANOTILHO, 2003, p. 531).
\end{abstract}

No atual Estado Democrático de Direito é essencial a (re)construção dos vínculos de solidariedade e, sobretudo, quanto aos deveres fundamentais, haja vista que como indivíduos numa sociedade, deve-se contribuir para o bem comum.

O que se pode destacar é uma hipersubjetivação, ou seja, o indivíduo passa a ser titular de direitos subjetivos como uma figura central do universo jurídico, o que Chevallier chama de "absolutização do eu", característico da pós-modernidade. Assim, "a relevância conferida a partir dos anos 1980 ao tema dos direitos do Homem, concebidos como 'direitos fundamentais', deu uma nova dimensão a esse processo de subjetivação: ele implica, com efeito, que os indivíduos são titulares, enquanto Homens, de direitos em face ao poder e dispõem dos meios de fazê-lo valer" (CHAVALLIER, 2009, p. 134-135).

A Constituição brasileira de 1988 teve o cuidado de garantir os direitos fundamentais, o que é muito importante, tendo em vista que proporciona uma vida digna as pessoas na nação, base para uma boa convivência, porém, não teve o mesmo zelo com os deveres fundamentais, que possuem um papel relevante na proteção e promoção dos direitos fundamentais.

Desse modo, surge a razão de ser solidário, no Estado Democrático de Direito, na atual conjuntura constitucional, tendo em vista o art. $3^{\circ}$, em que um dos objetivos da República brasileira é a construção de uma sociedade livre, justa e solidária (BRASIL, 1988).

Portanto, atuar em solidariedade significa um compromisso em relação ao outro, isto é "es la manera de actuar que impele a la voluntad individual y colectiva para buscar conscientemente la satisfacción de las necesidades básicas del 'otro'. Dado que la solidaridad es un comportamiento consciente, es una cualidad que solo pertenece a los seres humanos" (PEDRA, 2016).

A solidariedade garante liberdade, porém é preciso que as pessoas renunciem ao egoísmo. Ou seja, "la solidaridad no es caridad. La caridad nos obliga a ayudar a los otros por amor, sin que el otro tenga el derecho a una limosna o ayuda. En cambio, la solidaridad (normativa) no es un regalo, sino que es un derecho del 'otro"” (PEDRA, 2016).

Destarte, as pessoas em sociedade devem ter condutas compatíveis para com a realização dos valores constitucionais, por isso assumem deveres fundamentais para promoção dos ideais consagrados. Desse modo, a Constituição pode estabelecer deveres fundamentais tanto implícita como explicitamente, assim como o faz com os direitos fundamentais (PEDRA, 2016).

Há de ser ressaltado que, conforme Canotilho (2003, p. 532-533), não há simetria entre direitos e deveres, ou seja, que a cada direito fundamental protegido não pressupõe um dever correspondente, já que os deveres fundamentais possuem categoria autônoma. Assim, "vale aqui 
o princípio da assinalagmaticidade ou da assimetria entre direitos e deveres fundamentais, entendendo-se mesmo ser a assimetria entre direitos e deveres uma condição necessária de um estado de liberdade".

Portanto, pode ser facilmente constatado, que é inequívoco que houve um cômodo abandono da ideia de dever social, estimulada pelo marcante individualismo do tempo contemporâneo, que empalideceu e fez tornar-se anacrônica a imprescindível solidariedade social.

Cabe referir que, a maioria das Constituições do pós-segunda guerra aconteceram na sequência de períodos autoritários, motivo pelo qual, entende a 'quase-obsessão' por consagrar direitos e descurar deveres. No entanto, as circunstancias contemporâneas são outras e a categoria dos deveres fundamentais deve ser pensada como parte integrante do Estado Democrático de Direito.

Importante destacar, conforme bem ilustra Casalta Nabais (2009, p. 17-18), que:

[...] preocupam-se de uma maneira dominante, ou mesmo praticamente exclusiva, com os direitos fundamentais ou com os limites ao(s) poder(es) em que estes se traduzem, deixando por conseguinte, ao menos, aparentemente, na sombra os deveres fundamentais, esquecendo assim a responsabilidade comunitária que faz dos indivíduos seres simultaneamente livres e responsáveis, ou seja, pessoas.

Por conseguinte, a relevância do dever fundamental tem a ver com a satisfação das necessidades básicas essenciais das pessoas. Por isso, o dever fundamental se vincula diretamente a necessidade de contribuição para uma vida em comunidade (PEDRA, 2016). Como ressalta Canotilho (2003, p. 536), “as ideias de 'solidariedade' e de 'fraternidade' apontam para deveres fundamentais entre cidadãos".

Quanto aos direitos, Bonavides (2014, p. 678) afirma que fatores econômicos objetivos e reais seriam, portanto, decisivos para concretizá-los, pois "quanto mais desfalcada de bens ou mais débil a ordem econômica de um país constitucional, mais vulnerável e frágil nele a proteção efetiva dos sobreditos direitos".

Destaca-se a definição de Zagrebelsky (2011, p. 86) "son los deberes de todos hacia los demás los que están destinados a asentarse de una manera estable, como situación empírica permanente. En otras palabras, en las sociedades justas la categoría dominante es la de los deberes, no la de los derechos".

Com isso, pode-se constatar a importância dos deveres fundamentais no atual Estado Democrático de Direito, já que possuem o condão de concretizar os direitos fundamentais, sobretudo, o dever fundamental de pagar tributos, o qual constitui condição inafastável de qualquer cidadão numa sociedade que busca a concretização de políticas públicas em favor de sua comunidade.

Uma vez constatado o devido comprometimento dos cidadãos em honrar com a sua cota de contribuição para a sociedade, no que se refere aos pagamentos de seus tributos, estes indivíduos estarão colaborando solidariamente para a realização dos direitos fundamentais do próximo, ou seja, cooperando para a edificação de uma sociedade mais justa e comprometida com o outro. 
O estado democrático de direito e a tributação: entre os direitos e deveres fundamentais na (re)construção de uma sociedade solidária a partir do dever fundamental de pagar tributos

\title{
3 O DEVER FUNDAMENTAL DE PAGAR TRIBUTOS COMO INSTRUMENTO DE CONCRETIZAÇÃO DE DIREITOS
}

A concepção de deveres está intimamente ligada à ideia de solidariedade social. Só há deveres porque se convive em comunidade, e esta será tanto mais harmônica, quanto maior for a preocupação, de cada um, com o destino de todos.

Importante a reflexão de Comparato (2007. p. 24-25), quando diz que:

\begin{abstract}
Por outro lado, a ideia de que o princípio do tratamento da pessoa como um fim em si mesma implica não só o dever negativo de não prejudicar ninguém, mas também o dever positivo de obrar no sentido de favorecer a felicidade alheia constitui a melhor justificativa do reconhecimento, a par dos direitos e liberdades individuais, também dos direitos humanos à realização de políticas públicas de conteúdo econômico e social $[\ldots]$.
\end{abstract}

Comparato (2007, p. 65) refere que "a solidariedade prende-se à idéia de responsabilidade de todos pelas carências ou necessidades de qualquer indivíduo ou grupo social”. E ainda, que o fundamento ético desse princípio encontra-se no entendimento sobre justiça distributiva. Os direitos, portanto, se realizam por políticas públicas "destinadas a garantir amparo e proteção social aos mais fracos e mais pobres; ou seja, aqueles que não dispõem de recursos próprios para viver dignamente".

A solidariedade social resta mais evidente à medida que se examina o dever fundamental de pagar tributos. Assim, em épocas anteriores- absolutista e liberal- o cumprimento desse dever se orientava para conservação do Estado, de modo que não se encontrava um fundamento ético ou moral para a obrigação tributária. Havia um dever de obediência ao pagamento dos impostos, tendo em vista a autoridade soberana que a exigia.

Porém, com o Estado Social e Democrático de Direito, os tributos passaram a ter um conteúdo solidário, à medida que foi sendo empregado como instrumento a serviço da política social e econômica do Estado redistribuidor.

Portanto, os deveres fundamentais correspondem aos meios necessários para que o Estado possa atingir o bem comum, ou seja, a realização dos direitos fundamentais. Assim, os deveres fundamentais são os comportamentos positivos ou negativos impostos a um sujeito, em consideração e interesse que não são particularmente seus, mas sim em benefício de outros sujeitos ou de interesse geral da comunidade.

Cabe referir que, os deveres fundamentais, só excepcionalmente, têm natureza de norma diretamente aplicável, já que, na maior parte das situações, reclamam a existência de uma mediação legislativa para que possam ser exigidos. O dever fundamental de pagar tributos é um exemplo disso no Brasil, uma vez que necessita da mediação legislativa, ou seja, enquanto não sobrevier norma jurídica correspondente, o dever simplesmente inexiste.

Ainda, as normas constitucionais que estabelecem deveres fundamentais são, em geral, normas com baixa densidade normativa. Ao deixar de regular certas tarefas, a Constituição forma um instrumento democrático que possibilita confrontações políticas. Por outro lado, a abertura do sistema constitucional expressa um caráter incompleto e precário do conhecimento científico, dando espaço ao jurista para ampliar ou modificar o sistema (PEDRA, 2016).

Por isso, se fala numa necessidade de integração legislativa, pois mesmo os textos normativos redigidos de forma clara e precisa devem ser interpretados para esclarecer melhor seu conteúdo (PEDRA, 2016). 
A regulação dos deveres pela Constituição possui uma estrutura bifásica, ou seja, por um lado, guia o legislador ordinário para que, no exercício de suas funções, ponha os deveres como regra, já que possuem baixa densidade normativa. Por outro lado, a regulação constitucional é o fundamento para o exame da constitucionalidade dessa legislação (PEDRA, 2016).

Importante referir que "los deberes fundamentales tienen por objeto garantizar derechos fundamentales. Por lo tanto, la inercia del legislador para establecer los comportamientos obligatorios al sujeto del deber perjudica a los derechos fundamentales" (PEDRA, 2016).

É de se destacar que, uma sociedade precisa de recursos econômicos para se organizar, isto é, há necessidade de que existam fontes de recursos para financiar a existência digna das pessoas que nela sobrevive.

No caso brasileiro, há muitas omissões do legislador para regular as condutas do sujeito de dever, inclusive, para estabelecer sanções em caso de descumprimento, com o fim de promover os direitos dos indivíduos em sociedade. Resta uma reflexão sobre o assunto, de maneira que o legislativo possa se mostrar mais eficiente a partir de elementos coercitivos para a eficácia dos deveres fundamentais (PEDRA, 2016).

O financiamento para as políticas sociais, na sua maior parte, portanto, advém do pagamento de tributos, que são exigidos dos cidadãos para cumprir um dever ético e solidário de contribuir para o desenvolvimento da sociedade. Diante disso, submeter-se à tributação corresponde a um imperativo de liberdade. Tal ocorre porque ela corresponde à condição de possibilidade de concretização das promessas contidas nos direitos fundamentais, especialmente aqueles de cunho social.

Assim, o Estado assumiu o compromisso de corrigir as mazelas e promover o bem comum, notadamente a partir de políticas públicas, estas, por sua vez, financiadas pelos cidadãos, em grande parte, pelo dever fundamental de pagar tributos. Como ressalta Casalta Nabais (2009, p. 679):

Como dever fundamental, o imposto não pode ser encarado nem como um mero po-
der para o estado, nem como um mero sacrifício para os cidadãos, constituindo antes
o contributo indispensável a uma vida em comunidade organizada em estado fiscal.
Um tipo de estado que tem na subsidiariedade da sua própria ação (econômico-social)
e no primado da autorresponsabilidade dos cidadãos pelo seu sustento o seu verda-
deiro suporte. Daí que se não possa falar num (pretenso) direito fundamental a não
pagar impostos.

$\mathrm{O}$ atual Estado possui a característica de um Estado Fiscal, a partir do qual suas necessidades financeiras são geridas a partir do pagamento de tributos pelos cidadãos. Porém, deve-se levar em conta a capacidade contributiva dos indivíduos, já que "a capacidade contributiva constitui o pressuposto e o critério da tributação” (NABAIS, 2009. p. 688).

Assim, no atual modelo estatal, deve-se ter em conta a exigência da tributação de acordo com a capacidade contributiva, ou seja, uma concepção contemporânea de cidadania (compatível com o Estado Democrático de Direito) passa pelo adequado cumprimento do dever fundamental de pagar tributos, e isso, em face ao princípio da solidariedade social, ocorre sob dois enfoques: a) o dever fundamental de contribuir de acordo com a capacidade contributiva, justamente para que o Estado tenha os recursos necessários para realizar os direitos fundamentais e, com isso, propiciar a máxima eficácia ao princípio da dignidade da pessoa humana; b) o direito de não ser obrigado a contribuir acima das possibilidades- desproporcionalmente à capacidade contributiva- pois isso se constituiria afronta direta ao princípio da dignidade da pessoa, uma vez que o mínimo vital a uma existência digna restaria afetado. 
O estado democrático de direito e a tributação: entre os direitos e deveres fundamentais na (re)construção de uma sociedade solidária a partir do dever fundamental de pagar tributos

Tendo em vista o artigo 145, $\S 1^{\circ}$, da Constituição Federal de 1988, que prescreve: "Sempre que possível, os impostos terão caráter pessoal e serão graduados segundo a capacidade econômica do contribuinte, facultado à administração tributária, especialmente para conferir efetividade a esses objetivos, identificar, respeitados os direitos individuais e nos termos da lei, o patrimônio, os rendimentos e as atividades econômicas do contribuinte" (BRASIL, 1988), há necessidade, portanto, que a carga fiscal seja adequada à efetiva capacidade do cidadão.

Importante compreender que no atual Estado fiscal, como no caso do Brasil, as políticas sociais são financiadas pelo pagamento de tributos não-vinculados a uma atuação estatal específica, que são exigidos do cidadão pelo simples fato de pertencer à sociedade.

Assim, os tributos bilaterais, correspondem às taxas e contribuições de melhoria, e os unilaterais, correspondem aos impostos e às contribuições sociais não-sinalagmáticas, também chamados de impostos finalísticos. Por isso que, no caso do Brasil, é mais adequado falar em dever fundamental de pagar tributos não-vinculados ou desprovidos de bilateralidade, optandose, para fins desse artigo, simplesmente a definição de dever fundamental de pagar tributos.

Com o fim de garantir o bem comum, os deveres são indispensáveis numa sociedade, pois possuem uma dupla dimensão, ou seja, do ponto de vista subjetivo, os deveres estão orientados à igualdade material; portanto, garantem a repartição das tarefas que tutelam o interesse coletivo. Já, sob o ponto de vista objetivo, os deveres são elementos configuradores da própria ordem jurídica-política (CHULVI, 2001, p. 295-296).

A importância dada ao dever tributário, isto é, dever de contribuir, é enfatizada por Chulvi, ao referir que:

\begin{abstract}
Uno de los deberes que ha acompañado al Estado desde el mismo momento de su nacimiento ha sido el deber tributario. El paso del tiempo y la evolución en las formas históricas estatales han ido dejando su huella en el fundamento de este deber que ha pasado de ser concebido únicamente como medio para conseguir la necesaria financiación que permite la subsistencia del Estado a ser un instrumento al servicio de la política social y económica del Estado redistribuidor (2001, p. 296).
\end{abstract}

Assim, o cumprimento do dever tributário constitui “condición de vida para la comunidad porque hace posible el regular funcionamiento de los servicios estatales y el cumplimiento de las finalidades sociales que lleva a cabo el Estado" (CHULVI, 2001, p. 86).

Por outro lado, atualmente, há uma consciência social desfavorável à imposição do dever tributário, isto é, há uma resistência social em pagar tributos. Chulvi (2001, p. 298) define como objeção de consciência fiscal, que significa a "negativa del individuo, por motivos de conciencia, a someterse a la conducta jurídicamente exigible de contribuir al sostenimiento de los gastos públicos porque el destino final que se otorga a su contribución contraria su conciencia personal”.

Um elemento que deve ser combatido na atual sociedade é a evasão fiscal, que decorre especialmente do sentimento de inexistência de respostas estatais às demandas sociais, como também, da visível corrupção e desvios de recursos que assolam a administração pública, ou seja, não basta que a justiça esteja sendo feita; é fundamental que haja a percepção de que ela esteja sendo feita, e isso é condição de aceitabilidade de qualquer sistema fiscal.

Diante disso, nota-se que, o sistema tributário tem muito a contribuir, a partir do financiamento de políticas sociais, para realizar os direitos da sociedade, só que, para isso, é necessário que cada cidadão esteja disposto a assumir seus deveres, notadamente, o dever fundamental de pagar tributos, para a (re)construção dos vínculos de solidariedade como preconiza o atual Estado Democrático de Direito. 


\section{CONCLUSÃo}

No atual Estado Democrático de Direito é essencial a (re)construção dos vínculos de solidariedade e, sobretudo, quanto aos deveres fundamentais, haja vista que como indivíduos numa sociedade, deve-se contribuir para o bem comum.

Contudo, como consequência de grande parcela das Constituições advindas do Estado Providência, após períodos de repressão e totalitarismos, sobrevieram uma gama de direitos fundamentais instituídos pelos Estados, sem darem a devida atenção aos deveres fundamentais. $\mathrm{O}$ que não foi diferente com o Brasil, na Constituição de 1988, que previu inúmeros direitos aos indivíduos, porém, sem referir nos deveres.

Com a crise de financiamento dos Estados, notadamente pelo crescimento do déficit público, com descompasso entre receitas e despesas, ficou mais evidente a necessidade de se resgatar os deveres fundamentais, notadamente o dever de pagar tributos.

Portanto, atuar em solidariedade significa um compromisso em relação ao outro. A relevância do dever fundamental tem a ver com a satisfação das necessidades básicas essenciais das pessoas. Por isso, o dever fundamental de pagar tributos se vincula diretamente com a necessidade de contribuição para uma vida digna em comunidade.

Com isso, pode-se constatar a importância dos deveres fundamentais no atual Estado Democrático de Direito, já que possuem o condão de concretizar os direitos fundamentais, sobretudo, o dever fundamental de pagar tributos, o qual constitui condição inafastável de qualquer cidadão numa sociedade que busca a concretização de políticas públicas em favor de sua comunidade.

Uma vez constatado o devido comprometimento dos cidadãos em honrar com a sua cota de contribuição para a sociedade, no que se refere aos pagamentos de seus tributos, estes indivíduos estarão colaborando solidariamente para a realização dos direitos fundamentais do próximo, ou seja, cooperando para a edificação de uma sociedade mais justa e comprometida com o outro.

Há necessidade, portanto, de se acabar com a resistência ao pagamento de tributos, no Brasil, é fundamental o dever tributário. Porém, para isso, é preciso maior participação dos cidadãos nos processos de política social, é preciso que vejam o que tem sido realizado no país com sua contribuição, é imprescindível maior transparência dos gastos públicos, assim como, fiscalização e combate à evasão fiscal.

Desse modo, será possível a realização do dever fundamental de pagar tributos, minimizando as desigualdades e mazelas advindas de outros períodos. A efetivação dos direitos fundamentais, como preconizados na Constituição de 1988, são essenciais para se viver em sociedade, e o dever tributário contribui sobremaneira para este fim, pois concretiza a solidariedade entre os cidadãos.

\section{REFERÊNCIAS}

BACHOF, Otto. Normas Constitucionais inconstitucionais? Coimbra: Almedina, 1994.

BARROSO, Luís Roberto. Curso de Direito Constitucional Contemporâneo: os conceitos fundamentais e a construção do novo modelo. 4. ed. São Paulo: Saraiva, 2013.

BINENBOJM, Gustavo. A nova jurisdição constitucional brasileira: legitimidade democrática e instrumentos de realização. 2. ed. rev. e atual. Rio de Janeiro: Renovar, 2004. 
O estado democrático de direito e a tributação: entre os direitos e deveres fundamentais na (re)construção de uma sociedade solidária a partir do dever fundamental de pagar tributos

BONAVIDES, Paulo. Curso de Direito Constitucional. 29. ed. atual. São Paulo: Malheiros, 2014.

BRASIL. Constituição (1988). Constituição da República Federativa do Brasil de 1988. Disponível em: <http://www.planalto.gov.br/ccivil_03/constituicao/constitui\%C3\%A7ao.htm>. Acesso em: 30 jun. 2016.

BUFFON, Marciano. Tributação e dignidade humana: entre os direitos e deveres fundamentais. Porto Alegre: Livraria do Advogado, 2009.

CANOTILHO, José Joaquim Gomes. Direito Constitucional e Teoria da Constituição. 7. ed. Coimbra: Almedina, 2003.

CHAVALLIER, Jacques. O Estado pós-moderno. Belo Horizonte: Fórum, 2009.

CHULVI, Cristina Pauner. EI deber constitucional de contribuir al sostenimiento de los gastos públicos. Madrid: Centro de Estudios Políticos y Constitucionales, 2001.

COMPARATO, Fábio Konder. A afirmação histórica dos direitos humanos. 5. ed. rev. e atual. São Paulo: Saraiva, 2007.

DALLARI, Dalmo de Abreu. Elementos de teoria geral do estado. 30. ed. São Paulo: Saraiva, 2011.

FERREIRA FILHO, Manoel Gonçalves. Estado de direito e Constituição. 2. ed. rev. e ampl. São Paulo: Saraiva, 1999.

FIORAVANTI, Maurizio. Constituición: de la antiguidad a nuestros días. Madrid: Trotta, 2001.

GARCÍA-PELAYO, Manuel. As transformações do estado contemporâneo. Rio de Janeiro: Forense, 2009.

LOEWENSTEIN, Karl. Teoría de la Constitución. Barcelona: Ariel, 1979.

NABAIS, Jose Casalta. O dever fundamental de pagar impostos: contributo para a compreensao constitucional do estado fiscal contemporaneo. Coimbra: Almedina, 2009.

PEDRA, Adriano Sant'ana. Los deberes de las personas y la realizacion de los derechos fundamentales. In: Scielo (Recurso Eletrônico). p. 13-28. v. 12. no. 2. Santiago, 2014. Disponível em: < http://www.scielo.cl/pdf/estconst/v12n2/art02.pdf>. Acesso em: 01 jul. 2016.

STRECK, Lenio Luiz; MORAIS, José Luis Bolsan de. Ciência política e teoria do estado. 8. ed. rev. e atual. Porto Alegre: Livraria do Advogado, 2014.

TEIXEIRA, Anderson Vichinkeski. Teoria pluriversalista do direito internacional. São Paulo: Martins Fontes, 2011.

ZAGREBELSKY, Gustavo. El derecho dúctil: ley, derechos, justicia. Madrid: Trotta, 2011. 